\title{
Social Axioms: A Traditional Literature Review
}

\author{
Aafia Rasool ${ }^{1}$ and Syeda Shahida Batool $^{2} *$
}

\begin{abstract}
The study was conducted to perform a comprehensive overview of the available documented studies on social axioms to identify the relevant literature and research gaps in the field of social axioms. The empirical studies carried out in the different countries that have been classified by publication years, research designs, and methods of studies. The paper presents a review of 72 published articles in journals of the different countries during 2002 to date, thus, an exploration reveals that social axioms play a considerable role in social behaviors and health of individuals, and they function differently in different cultures. This review would be helpful for the future researchers to direct their work towards the significance of social axioms in the different domains of life. Implications of this review have been discussed.
\end{abstract}

Keyword: Social Axioms; Social Behaviors; Health; Literature Review.

\section{Introduction}

Social axioms are viewed as the generalized beliefs about people, physical and social surroundings, and the spiritual world. These generalized beliefs are derived from personal experiences and process of socialization such as educational system and family. Individuals use these beliefs in order to direct their actions, as they are helpful in dealing with effective functioning and survival problems (Bond et al., 2004). The study of general beliefs as proposed by Leung et al. (2002) and the Social Axioms Survey has been developed to measure such beliefs.

Leung and Bond (2004) have identified five-factor structure of social axioms, as based on participants' data gathered from the different nations. These five factors are social cynicism, social complexity, reward for application; fate control and religiosity. Social cynicism denotes to a cynical perception of human nature, a lack of faith in social institutions, and a lack of ethical means to accomplish a goal. Social complexity relates to the idea that there are no strict laws, but rather several ways to achieve the given result and that variation in human actions are common. Reward for application denotes the idea that investment of human resources (such as careful planning, expertise and knowledge) will lead to positive consequences. Fate control belief denotes that there are predetermined life outcomes and that there are certain ways to affect these outcomes. Religiosity denotes to the belief in the existence of Supreme Being and the roles of religious practice.

\footnotetext{
1 Department of Psychology, Government College University, Lahore, Pakistan.

2 Department of Psychology, Government College University, Lahore, Pakistan.
}

*)Corresponding Author.

Email: shahidaphd@yahoo.com 
Social axioms have four major functions $t$ which assist the existence of humans: i) value-expression: expressing one's values, ii) knowledge: assisting individuals to understand the world around them, iii) instrumentality: promoting the achievement of significant objectives, and iv) ego-defense: assist individuals to defend their self-worth (Leung et al., 2002). Social axioms act as universal knowledge about the universe so that in the specific domains they work as guiding principles for beliefs. In view of that, social axioms predict attitudinal variables in many fields of psychological inquiry including the political attitudes (Keung \& Bond, 2002), paranormal beliefs (Singelis et al., 2003), vocational interest (Bond et al., 2004), and attitudes towards helpseeking (Kuo et al., 2006). Social axioms still have usefulness for adaptation and survival. A study conducted by Kurman and Ronen-Eilon (2004) indicated that if immigrants had correct knowledge of social axioms that described their host cultures, and they would adapt better.

Social axioms act as guiding principles to guide progress towards achieving the essential life goals. This belief reflects how a means is linked to a specific end and the subjective opinion of the likelihood in which a particular means in a given situation that leads to a particular end (Vroom, 1964). In view of that, the various social axioms may combine to the given end with the various prescribed means. For instance, reward for application describes the contingency between expended efforts and earned reward, however; social cynicism describes the contingency between one's social power and likely reward. More precisely, in a conflict situation, reward for application predicts the preference for collaborative and compromise tactics to make a better decision, whereas social cynicism predicts a competitive orientation involving the exercise of control or protection by a collaborator against its possible use (Bond et al., 2004; Chen \& Zhang, 2004). Likewise, reward for application predicts preference for the use of persuasive influence techniques, whereas social cynicism predicts assertive and relationship based strategies, which are again power and status advantage exercises (Fu et al., 2004).

Social axioms thus, direct selections, their generation and choices, leading to the achievement of situational ally-based objectives as chosen by the belief-holder. Social axioms have the profound consequences for our subjective well-being and self-worth. Social axioms illustrate the instrumentality of multiple means to achieve a given goal, and they can predict how people deal with life's difficulties and accomplish well-being and selfworth. For instance, the use of a problem-solving coping style is predicted by reward for application, while passive modes of coping, such as wishful thinking and distancing is predicted by fate control (Bond et al., 2004). While self-worth and well-being are common goals: it is an essential fact to remember that discrepancies between individuals exist when evaluating the efficacy of the different tactics. The people high in social cynicism, for instance, displayed the more negative attitudes towards finding out the support through professional services (Kuo et al., 2006). This outcome can serve as 
one of the reasons that accounts for the robust, and finding that social cynicism is constantly correlated with a more pessimistic psychological state including low satisfaction with life (Chen et al., 2006; Lai et al., 2007), psychological distress (Kuo et al., 2006), and death ideation (Hui et al., 2007).

\subsection{Objective of the Study}

The objective of this article was to review maximum the published empirical studies which have examined social axioms in the different contexts around the globe, and the gap in literature that exists to identify directions for the future studies.

\section{Methodology}

To analyze the relevant research work; the present study utilized the traditional literature review approach (Jesson et al., 2011). The template of PRISMA flowchart (Moher et al., 2009) was used to describe the procedure of collection and rejection of studies for the literature review on the social axioms.

\subsection{Literature Search}

The keywords employed to find out the literature in Science Direct, Taylor \& Francis, Google Scholar, JSTOR, Elsevier and APA PsycNet databases were "social axioms", "social axioms in psychology" and "general beliefs". Initially, 1382 research publications were found through these databases. Then, we confined our search to the subject Psychology, and 98 research publications were selected. Among such the publications, only 91 were published in English language. Thus, the present paper aimed to cover only research articles whereas dissertations, conference papers and book publications were excluded and, finally 72 articles as selected for the review (see figure 1). 


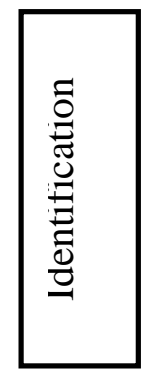

Records identified through

searching databases

Science Direct: 322

Additional records identified through other sources

Taylor \& Francis: 232

$(\mathrm{n}=0)$

Google Scholar: 574

JSTOR: 66
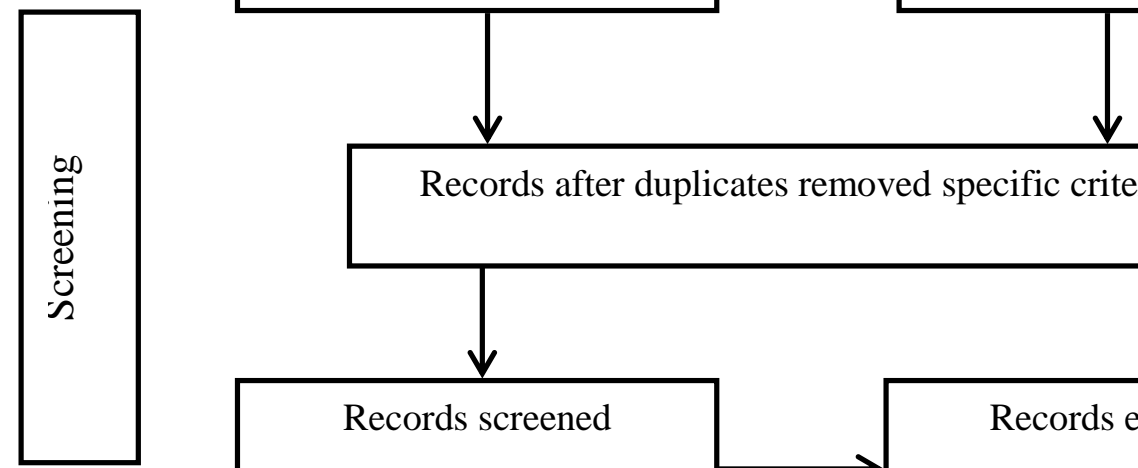

Records after duplicates removed specific criteria

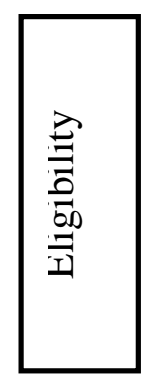

$(n=98)$

Records excluded

$(n=7)$
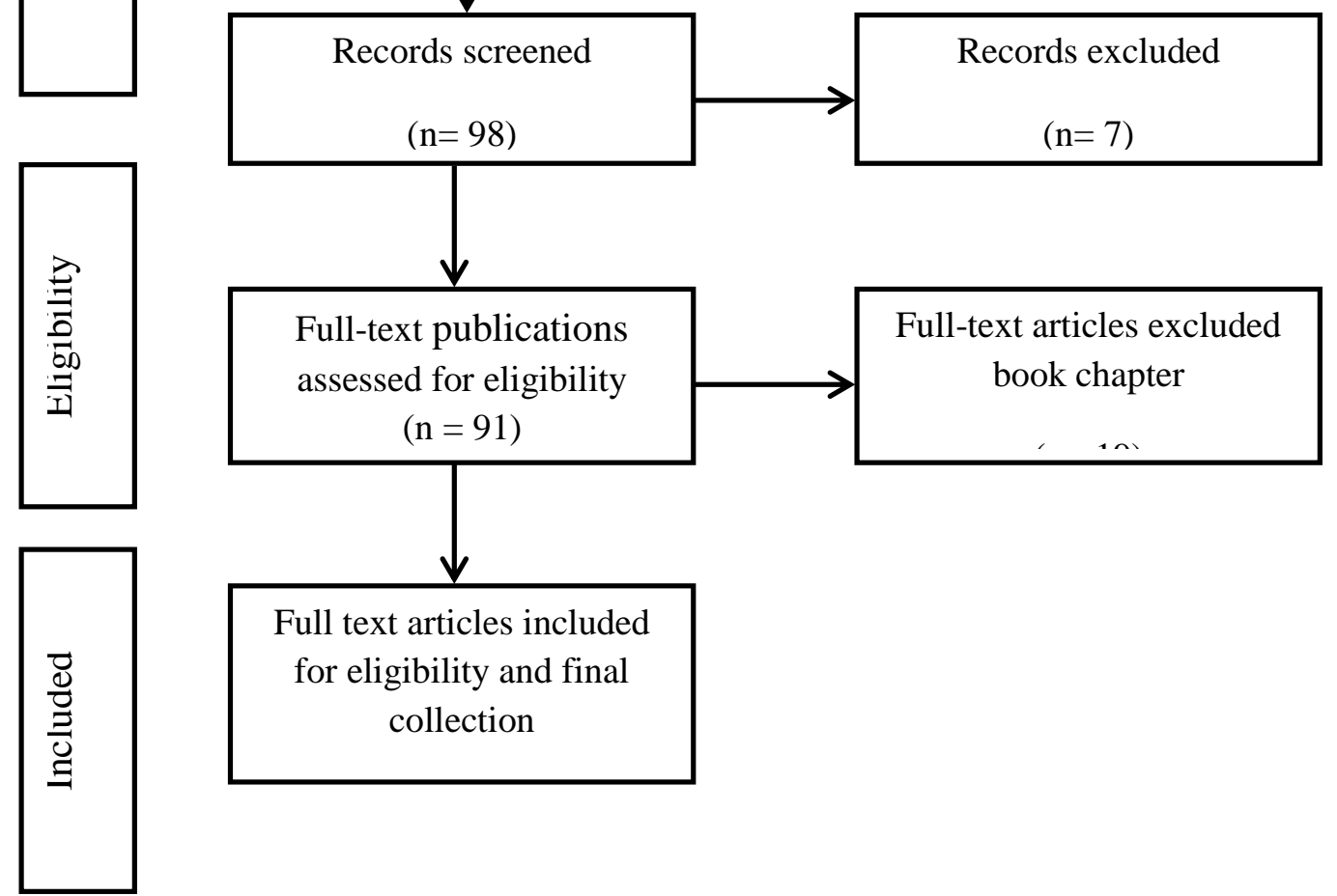

Figure 1: PRISMA flowchart 


\subsection{Quality Assessment}

To ensure the quality and relevance of the scholarly literature included in the review process, any kind of duplication, abstracts and conclusions of the papers were carefully reviewed for analysis.

\subsection{Articles Included for Analysis}

The final 72 full text articles were utilized for the analysis process which included year-wise distribution of articles and distribution of articles by research methodologies.

\subsection{Year-wise Distribution of Articles}

This review article includes the empirical studies in Psychology on the social axioms conducted around the globe since 2002, to date. However, such the term social axioms were first defined by Leung et al. (2002). For organizing the data, we divided total period into two decades. Out of 72 articles, 40 articles were published in the first decade during 2002 to 2011, whereas 32 articles were published in the second decade during 2012 to date.

The figure 2 shows the year base graph of publications that the year 2010 and 2012 points out the highest number with the 10 and 9 articles each year respectively.

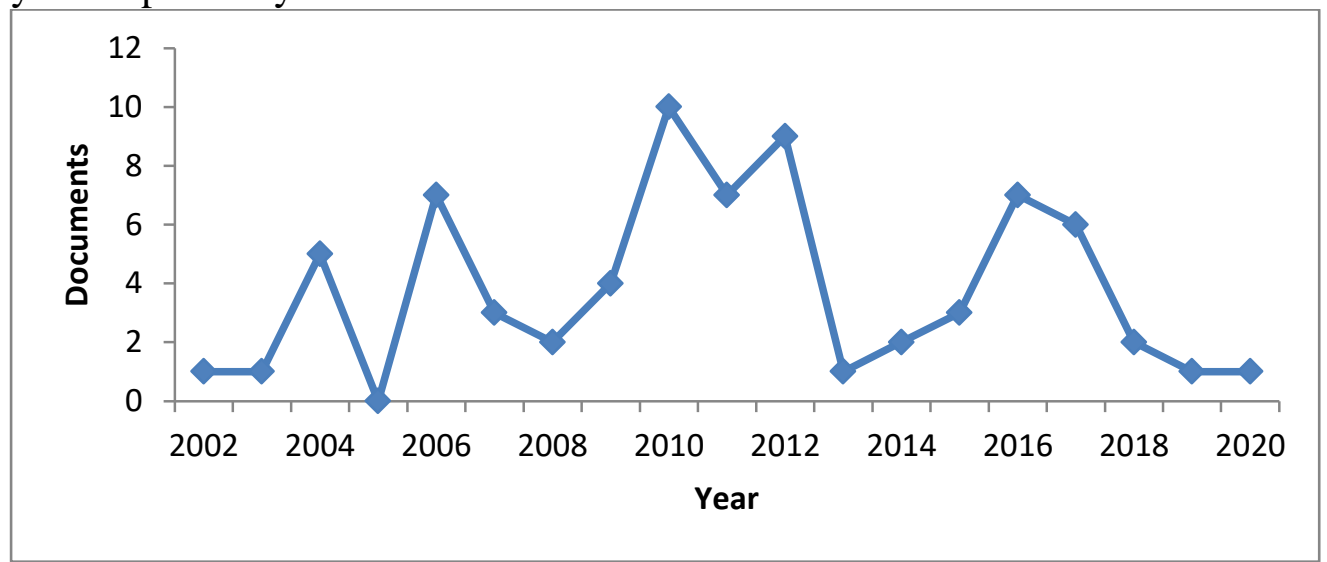

Figure 2: Year-wise Publications

\subsection{Distribution of Publications by Research Methodologies}

Out of 72 articles, 69 articles employed to the quantitative methods (such as cross-sectional, longitudinal, comparative, correlational, cross-cultural and experimental designs). Three articles having the mixed methods (both quantitative and qualitative). These results s figured out that research on the social axioms is dominated by the quantitative method.

\section{Results and Discussion}

The review of literature resulted that the decade from 2002 to 2011 included research papers on the social axioms dominated by quantitative studies with major focus on industrial, positive and social psychology. The second decade 
included the research papers from 2012 to date and, this decade as dominated through the cross-cultural studies with greater emphasis on social psychology.

\subsection{Research Trends in the First Decade (from 2002 to 2011)}

Research on the social axioms in the first decade initiated with the development and validation of Social Axioms Survey (Leung et al., 2002) by (Singelis et al., 2003). Bond et al. (2004) further, as explored cultural level dimensions of social axioms, and found two dimensions - societal cynicism and dynamic externality. Another cross-cultural study indicated that at the individual level structure, equivalence of social axioms was well supported, however; the cross level equivalence was partially supported (Cheung et al., 2006). Social axioms survey was further replicated in South Africa. Thus, the results of exploratory factor analysis showed four interpretable factors - social cynicism, fate control, reward for application and religiosity (Barnard et al., 2008). Gari et al. (2009) conducted a cross-cultural study and found that nearly maximum equivalence as reached with the overall factor structure, but some in equivalence remained still present for specific factors among the clusters of countries.

With reference to industrial psychology, studies found that the different dimensions of social axioms predicted the perceived effectiveness of the three types of influence strategy (Fu et al., 2004), conscientiousness significantly having moderate the negative association of social cynicism with interpersonal justice (Peng \& Zhou, 2009), inverse relationship between social cynicism and satisfaction with job was significantly moderated by perceived well-being only when perceived well-being was low (Leung et al., 2010), participants high in social cynicism felt less guilty when they violated a work regulation norm (Ersoy et al., 2011).

With regard to the field of social psychology, such the studies found that social axioms contributed moderate predictive power, in conflict resolution, vocational choices and coping styles (Bond et al., 2004). Age, gender, perceived stress, ethnicity and two social axiom factors (interpersonal harmony and social cynicism) were the significant predictors of help-seeking attitudes (Kuo et al., 2006); social axioms were associated with value types in interpretable and meaningful way (Leung et al., 2007); social cynicism was negatively predicted by self-esteem whereas reward for application was positively predicted by relationship harmony (Wong et al., 2010);meanwhile the significant indirect effects of fate control belief was reported on negative mood and problem gambling through gambling expectancy bias and gambling self-efficacy (Tang \& $\mathrm{Wu}, 2010$ ); and the positive association between intention to quit and relationship conflict found the insignificant when social cynicism was high (Li et al., 2011); thus, the significant contribution of social axioms to personal characteristics in behavior prediction was found (Kurman, 2011); while the higher level of children's acceptance, reward for application belief, religiosity belief and better relationships with their partner were found 
in HIV infected children's mothers as compared to mothers of healthy children (Tartakovsky \& Hamama, 2011).

With respect to the area of positive psychology; it was resulted that social axioms were significantly associated with satisfaction of social life (Chen et al., 2006; Burgess, 2011). Another study found the impact of social cynicism on satisfaction with life through the mediating role of self-esteem ( $\mathrm{Li}$ et al., 2007); gratitude was predicted by reward for application, social complexity and religiosity whereas, perspective taking was predicted by social cynicism and social complexity (Joshanloo et al., 2010); social cynicism was linked to less adaptive self-regulatory orientations, which sequentially put at risk subjective well-being, however reward for application was linked to more adaptive self-regulatory orientations that improved subjective well-being (Hui \& Bond, 2010); the impact of weight esteem on self-esteem was moderated by social cynicism (Lam et al., 2010); and relationship of insecure attachment style with life satisfaction was mediated by social cynicism and reward for application (Mak et al., 2011).

In relation to cultural psychology, the prevalent studies have found that social axioms were the significant descriptors of a culture (Kurman \& RonenEilon, 2004), cultural values as well as social beliefs predicted individual's choice of conflict resolution strategy (Safdar et al., 2006); social axioms predicted acculturation orientations of English Canadians towards British and Arab Muslim immigrants (Safdar et al., 2008). As educational psychology concerns and these studies found the relationship of dimensions of social axioms with achievement goals and learning strategies (Bernardo, 2004), academic achievement (Zhou et al., 2009; Leung et al., 2010). In the field of personality psychology, relationship as found between social axioms and personality (Chen et al., 2006; Chen et al., 2006). As the field of abnormal psychology concerns, it was found that people higher in fate control belief and lower in religiosity belief scored higher on death anxiety (Hui et al., 2007), and social cynicism positively and reward for application negatively predict suicidal ideation (Chen et al., 2009).

\subsection{Research Trends in the Second Decade (from 2012 to Date)}

Some validation studies were conducted in the second decade. In relation to development of social axioms survey II, indicating that SAS II was more reliable than the original SAS (Leung et al., 2012), it was further validated in South African context (Barnard et al., 2017).

With reference to the domain of social psychology; these studies found that fate control was inversely associated with implicit attitudes (Ma et al., 2012); self-effacement was significantly predicted by reward for application whereas enhancement of others and avoiding attention was significantly predicted by social cynicism (Bond et al., 2012) ,the relationships of perceived causes to remedies were greater than those of social axioms and values (Chen \& Bond, 2012); for the values of self-direction, absolute reciprocity had been shown with the absence of contemporary 
associations between values and beliefs (Goodwin et al., 2012); and workfamily conflict was found to be a significant forerunner of distress, but it put forth little influence on social cynicism (Li \& Leung, 2012). Furthermore, reward for application and social cynicism was positively and social complexity was negatively associated to hierarchic self-interest i.e., personal value preferences (Dragolov \& Boehnke, 2015), self-views as a proximal force and world views as a distal force appeared to matter in subjective evaluation of people's lives (Chen et al., 2016); social axioms significantly predicted modest behavior (Chen et al., 2017), religiosity, reward for application, and fate control were related to dyadic adjustment (Iliescu et al., 2017); and relation between need frustration and social cynicism was moderated by implicit affiliation-intimacy motive (Hofer et al., 2017).

With regard to Abnormal psychology, positive association was found between social cynicism and emotional weariness (Tartakovsky et al., 2012). Regarding educational psychology, it was found that university teachers had demonstrated considerably higher scores of power-distance, social cynicism, religiosity and reward for application than the secondary school teachers (Gavreliuc \& Gavreliuc, 2012); predictors for flourishing appeared as reward for applications, social cynicism and school belonging (Li et al., 2020). With respect to positive psychology, studies found that social cynicism was negatively and reward for application was positively associated with hope (Bernardo, 2013), social axioms predicted locus-of-hope (Bernardo \& Nalipay, 2016), relationship of religiosity and reward for application with posttraumatic growth was mediated by adaptive cognitive processing of trauma (Nalipay et al., 2016).

In industrial psychology, it was found that fate control, social cynicism and religiosity have moderating effects on firm reputation (West et al., 2016). Additionally, in the area of intelligence, studies showed that social complexity belief positively linked with cultural intelligence development and this association was mediated by the perception of disconfirmation (Alexandra, 2018).

\subsection{Implications of Study}

The systematic review helps us to draw accurate conclusions and reduce biasness. The findings from different researches make it easier for the user to access the information and understand it in a comprehensive way. All the available research directions are mentioned, so it gives a better idea to articulate future work. The research gaps can easily be identified and future researchers can design studies focusing on the neglected areas of the phenomenon social axioms. The findings of the empirical studies highlighted the favorable and harmful effects of social axioms.

\subsection{Limitations}

The scientific papers obtained from JSTOR, Taylor and Francis, Google Scholar, Elsevier, APA PsycNet and Science Direct is included in this 
literature review article. Yet some research paper may have been left out due to the journals' accessibility. We could not discuss some significant work because sources including eBooks, dissertations and conference proceedings were excluded to maintain the homogeneity of the data.

\subsection{Future Recommendations}

In the light of literature review, we provide following recommendations for the future studies:

- The previous studies mainly relied on non-probability sampling technique, so it is suggested to incorporate probability samples in future studies as well;

- A small number of studies have reported the role of demographic variables in association with social axioms, hence, we recommend to assess the significance of demographic variables along with psychosocial variables in future studies;

- In order to exhibit causal directionality, experimental and longitudinal studies should be carried out in future;

- Literature review displays leaning towards the quantitative research, as out of 72 studies, only three used the mixed method designs and the rest of them relied on a quantitative design. Hence, it is recommended to utilize the qualitative research designs too.

- The sample selection relied heavily on university students; thus, the results could not be mapped on the general population. Therefore, it is recommended to carry out the future research on diverse samples;

- The focus of the majority of studies was on industrial, social and positive areas of psychology further, a renewed focus on areas like, clinical and developmental psychology would change the prevailed trend.

\section{Conclusion}

Literature review of empirical studies published in the different journals from 2002 , to date in the field of social axioms reveals the significance of this attribute in different fields of life. Most of the reviewed studies were the quantitative in nature which indicates that the research on social axioms is dominated by the quantitative methods. The literature review provides an ample evidence to conclude that social axioms play an important role in our functioning in the numerous areas and contexts of life. For instance, social cynicism appeared to be negatively correlated with lower self-esteem, lower interpersonal trust, and higher social anxiety. Social cynicism in many studies positively correlated with a pessimistic psychological state, such as lower life satisfaction, psychological distress, and death ideation. Whereas, social complexity appeared to be positively correlated with cognitive flexibility, intelligence, coping and adjustment. Empirical studies also show that social axioms function differently in different cultures. We may conclude that major 
work on social axioms has been done in the fields of positive, industrial and social psychology and it would be a good contribution if the further work is directed towards other fields such as clinical psychology and health psychology.

\section{References}

Alexandra, V. (2018). The roles of social complexity belief and perceived contact characteristics in cultural intelligence development among individuals receiving contact based training. Journal of Cross-Cultural Psychology, 49(8), 1283-1301.

Alexandra, V., Torres, M. M., Kovbasyuk, O., Addo, T. B., \& Ferreira, M. C. (2017). The relationship between social cynicism belief, social dominance orientation, and the perception of unethical behavior: a crosscultural examination in Russia, Portugal, and the United States. Journal of Business Ethics, 146(3), 545-562.

Aqueveque, C., \& Encina, C. (2010). Corporate behavior, social cynicism, and their effect on individuals' perceptions of the company. Journal of Business Ethics, 91(S2), 311-324.

Barnard, A., Meiring, D., \& Rothmann, I. (2017). The factor structure of the Social Axioms Survey II (SASII) in the South African context. Journal of Psychology in Africa, 27(6), 522-529.

Barnard, A., Rothmann, S., \& Meiring, D. (2008). The cross-cultural application of the social axioms survey in The South African police service. SA Journal of Industrial Psychology, 34(2).

Bernardo, A. B. (2013). Hope grounded in belief: Influences of reward for application and social cynicism on dispositional hope. Scandinavian Journal of Psychology, 54(6), 522-528.

Bernardo, A. B. I. (2004). Culturally-rooted beliefs and learning: Exploring the relationships among social axioms, achievement goals, and learning strategies of Filipino college students. Philippine Journal of Psychology, 37(2), 79-100.

Bernardo, A. B., \& Nalipay, M. J. (2016). Social axioms as social foundations of locus-of-hope: A study in three Asian cultural groups. Personality and Individual Differences, 95, 110113.

Bond, M. H., Leung, K., Au, A., Tong, K.-K., \& Chemonges-Nielson, Z. (2004). Combining social axioms with values in predicting social behaviors. European Journal of Personality, 18(3), 177-191.

Bond, M. H., Leung, K., Au, A., Tong, K.-K., Carrasquel, S. R. D., Murakami, F., Lewis, J. R. (2004). Culture-level dimensions of social axioms and their correlates across 41 cultures. Journal of Cross-Cultural Psychology, $35(5), 548-570$.

Bond, M. H., Lun, V. M.-C., Chan, J., Chan, W. W.-Y., \& Wong, D. (2012). Enacting modesty in Chinese culture: The joint contribution of personal characteristics and contextual features. Asian Journal of Social Psychology, 15(1), 14-25. 
Burgess, S. M. (2011). Social axioms: A new culture measure for South African business research. South African Journal of Business Management, 42(4), 1-22.

Byza, O. A., Schuh, S. C., Dörr, S. L., Spörrle, M., \& Maier, G. W. (2017). Are two cynics better than one? Toward understanding effects of leader-follower (in-) congruence in social cynicism. Journal of Organizational Behavior, 38(8), 1246-1259.

Chen, L., \& Zhang, J. (2004). Relation between general social beliefs and interpersonal conflict resolution styles. Chinese Journal of Clinical Psychology, 12, 151-153.

Chen, S. X., \& Bond, M. H. (2012). Lay beliefs about psychological and social problems among adolescents: motivational and cognitive antecedents1. Journal of Applied Social Psychology, 42(1), 170-194.

Chen, S. X., Bond, M. H., \& Cheung, F. M. (2006). Personality correlates of social axioms: Are beliefs nested within personality? Personality and Individual Differences, 40(3), 509-519.

Chen, S. X., Cheung, F. M., Bond, M. H., \& Leung, J.-P. (2006). Going beyond self-esteem to predict life satisfaction: The Chinese case. Asian Journal of Social Psychology, 9(1), 2435.

Chen, S. X., Fok, H. K., Bond, M. H., \& Matsumoto, D. (2006). Personality and beliefs about the world revisited: Expanding the nomological network of social axioms. Personality and Individual Differences, 41(2), 201-211.

Chen, S. X., Lam, B. C. P., Wu, W. C. H., Ng, J. C. K., Buchtel, E. E., Guan, Y., \& Deng, H. (2016). Do people's world views matter? The why and how. Journal of Personality and Social Psychology, 110(5), 743-765.

Chen, S. X., Ng, J. C. K., Buchtel, E. E., Guan, Y., Deng, H., \& Bond, M. H. (2017). The added value of world views over self-views: Predicting modest behaviour in Eastern andWestern cultures. British Journal of Social Psychology, 56(4), 723-749.

Chen, S. X., Wu, W. C. H., \& Bond, M. H. (2009). Linking family dysfunction to suicidal ideation: Mediating roles of self-views and world-views. Asian Journal of Social Psychology, 12(2), 133-144.

Cheung, M. W.-L., Leung, K., \& Au, K. (2006). Evaluating Multilevel Models in Cross-Cultural Research. Journal of Cross-Cultural Psychology, 37(5), 522-541.

Dangel, T. J., Webb, J. R., \& Hirsch, J. K. (2018). Forgiveness and Suicidal Behavior: Cynicism and Psychache as Serial Mediators. The Journal of Psychology, 152(2), 77-95.

Dragolov, G., \& Boehnke, K. (2015). Social Axioms as Mediators Between Culture-Level and Individual-Level Values. Journal of Cross-Cultural Psychology, 46(6), 772-788.

Ersoy, N. C., Born, M. P., Derous, E., \& Molen, H. T. V. D. (2011). Effects of work-related norm violations and general beliefs about the world on feelings of shame and guilt: A comparison between Turkey and the Netherlands. Asian Journal of Social Psychology, 14, 50-62. 
Fu, P. P., Kennedy, J., Tata, J., Yukl, G., Bond, M. H., Peng, T.-K., Cheosakul, A. (2004). The impact of societal cultural values and individual social beliefs on the perceived effectiveness of managerial influence strategies: A Meso Approach. Journal of International Business Studies, 35(4), 284-305.

Gari, A., Mylonas, K., \& Panagiotopoulou, P. (2009). Dimensions of Social Axioms and Alternative Country-Clustering Methods. In A. Gari \& K. Mylonas (Eds.), Quod erat demonstrandum: from herodotus' ethnographic journeys to cross-cultural research, Athens: Pedio Books Publishing.

Gavreliuc, A., \& Gavreliuc, D. (2012). Social axioms, cultural dimensions and personal autonomy in Romanian educational field. Procedia-Social and Behavioral Sciences, 33, 223-227.

Goodwin, R., Polek, E., \& Bardi, A. (2012). The temporal reciprocity of values and beliefs: a longitudinal study within a major life transition. European Journal of Personality, 26(3), 360-370.

Guan, Y., Bond, M. H., Dinca, M., \& Iliescu, D. (2010). Social axioms among Romanians: Structure and demographic differences. Romanian Journal of Applied Psychology, 12(2), 48-53.

Hofer, J., Busch, H., Raihala, C., Solcova, I. P., \& Tavel, P. (2017). The higher your implicit affiliation-intimacy motive, the more loneliness can turn you into a social cynic: A cross-cultural study. Journal of Personality, 85(2), 179-191.

Hui, C. M., \& Bond, M. H. (2010). Relationship between social axioms and subjective well- being: The role of self-regulation. Journal of Psychology in Chinese Societies, 11(1), 29-52.

Hui, V. K.-Y., Bond, M. H., \& Ng, T. S. W. (2007). General beliefs about the world as defensive mechanisms against death anxiety. OMEGA Journal of Death and Dying, 54(3), 199-214.

Iliescu, D., Dinca, M., \& Bond, M. H. (2017). The increment of social axioms over broad personality traits in the prediction of dyadic adjustment: an investigation across four ethnic groups. European Journal of Personality, $31(6), 630-641$.

Jesson, J. K., Matheson, L., \& Lacey, F. M. (2011). Doing your literature review: traditional and systematic techniques. SAGE.

Joshanloo, M., Afshari, S., \& Rastegar, P. (2010). Linking social axioms with indicators of positive interpersonal, social and environmental functioning in Iran: An exploratory study. International Journal of Psychology, 45(4), 303-310.

Kaushal, R., \& Kwantes, C. T. (2006). The role of culture and personality in choice of conflict management strategy. International Journal of Intercultural Relations, 30(5), 579-603.

Keung, D. K.-Y., \& Bond, M. H. (2002). Dimensions of political attitudes and their relations with beliefs and values in Hong Kong. Journal of Psychology in Chinese Societies, 3(1), 133-154. 
Kuo, B. C. H., Kwantes, C. T., Towson, S., \& Nanson, K. M. (2006). Social beliefs as determinants of attitudes toward seeking professional psychological help among ethnically diverse university students. Canadian Journal of Counselling, 40(4), 224241.

Kurman, J. (2011). What I do and what I think they would do: Social axioms and behaviour. European Journal of Personality, 25(6), 410-423.

Kurman, J., \& Ronen-Eilon, C. (2004). Lack of knowledge of a culture's social axioms and adaptation difficulties among immigrants. Journal of Cross-Cultural Psychology, 35(2), 192-208.

Lai, J. H.-W., Bond, M. H., \& Hui, N. H.-H. (2007). The role of social axioms in predicting life satisfaction: a longitudinal study in Hong Kong. Journal of Happiness Studies, 8(4), 517535.

Lam, B. C. P., Bond, M. H., Chen, S. X., \& Wu, W. C. H. (2010). Worldviews and individual vulnerability to suicide: The role of social axioms. European Journal of Personality, 24, 602-622.

Lam, B. C. P., Mak, I. N. W., \& Walker, G. A. (2010). The role of social beliefs in body image research: A cross-cultural examination of Australian and Hong Kong Chinese college women. Journal of Psychology in Chinese Societies, 11(1), 9 - 28.

Leung, C. H. Y., Chen, S. X., \& Lam, B. C. P. (2010). Where there's a will, there's a way: The mediating effect of academic aspiration between beliefs and academic outcomes. Journalof Psychology in Chinese Societies. 11(1), 53-72.

Leung, K., \& Bond, M. H. (2004). Social axioms: A model for social beliefs in multicultural perspective. Advances in Experimental Social Psychology, 119-197.

Leung, K., Au, A., Huang, X., Kurman, J., Niit, T., \& Niit, K.-K. (2007). Social axioms and values: A cross-cultural examination. European Journal of Personality, 21(2), 91-111.

Leung, K., Bond, M. H., Carrasquel, S. R. D., Muñoz, C., Hernández, M., Murakami, F., Singelis, T. M. (2002). Social Axioms. Journal of CrossCultural Psychology, 33(3), 286-302.

Leung, K., Ip, O. K., \& Leung, K.-K. (2010). Social cynicism and job satisfaction: a longitudinal analysis. Applied Psychology, 59(2), 318-338.

Leung, K., Lam, B. C. P., Bond, M. H., Conway, L. G., Gornick, L. J., Amponsah, B., ... Zhou, F. (2012). Developing and evaluating the social axioms survey in eleven countries. Journal of Cross-Cultural Psychology, 43(5), 833-857.

Leung, K., Li, F., \& Zhou, F. (2012). Sex differences in social cynicism across societies. Journal of Cross-Cultural Psychology, 43(7), 1152-1166

Li, F., \& Leung, K. (2012). Effects of evaluation of societal conditions and work-family conflict on social cynicism and distress: a longitudinal analysis1. Journal of Applied Social Psychology, 42(3), 717-734.

Li, F., Zhou, F., \& Leung, K. (2011). Expecting the worst: moderating effects of social cynicism on the relationships between relationship conflict and 
negative affective reactions. Journal of Business and Psychology, 26(3), 339-345.

Li, Y., Tong, K. K., Tao, V. Y. K., Zhang, M. X., \& Wu, A. M. S. (2020). Testing the associations among social axioms, school belonging, and flourishing in university students: a two-year longitudinal study. Applied Psychology: Health and Well-Being.

Ma, L., Chen, S., Zhou, M., \& Zhang, J. (2012). Social axioms and implicit attitudes about people with disabilities. Social Behavior and Personality: an International Journal, 40(2), 251-258.

Mak, M. C. K., Han, Y. M. Y., You, J., Jin, M., \& Bond, M. H. (2011). Building life satisfaction through attachment to mother and beliefs about the world: social axioms as mediators intwo cultural groups. Mental Health, Religion \& Culture, 14(3), 223-239.

Malham, P. B., \& Saucier, G. (2014). Measurement invariance of social axioms in 23 countries. Journal of Cross-Cultural Psychology, 45(7), 1046-1060.

Moher, D., Liberati, A., Tetzlaff, J., \& Altman, D. G. (2009). Reprintpreferred reporting items for systematic reviews and meta-analyses: The PRISMA Statement. Physical Therapy, 89(9), 873-880.

Nalipay, M. J. N., Bernardo, A. B. I., \& Mordeno, I. G. (2016). Posttraumatic growth in survivors of a natural disaster: the role of social axioms of religiosity, reward for application, and social cynicism. The Journal of Positive Psychology, 12(4), 342-353.

Peng, Z., \& Zhou, F. (2009). The moderating effect of supervisory conscientiousness on the relationship between employees' social cynicism and perceived interpersonal justice. Social Behavior and Personality: An International Journal, 37(6), 863-864.

Safdar, S., Dupuis, D. R., Lewis, R. J., El-Geledi, S., \& Bourhis, R. Y. (2008). Social axioms and acculturation orientations of English Canadians toward British and Arab Muslimimmigrants. International Journal of Intercultural Relations, 32(5), 415-426.

Safdar, S., Lewis, J. R., \& Daneshpour, M. (2006). Social axioms in Iran and Canada: intercultural contact, coping and adjustment. Asian Journal of Social Psychology, 9(2), 123-131.

Saucier, G., Kenner, J., Iurino, K., Malham, P. B., Chen, Z., Thalmayer, A. G., ... Altschul, C. (2015). Cross-cultural differences in a global "survey of world views." Journal of Cross Cultural Psychology, 46(1), 53-70.

Singelis, T. M., Hubbard, C., Her, P., \& An, S. (2003). Convergent validation of the social axioms survey. Personality and Individual Differences, 34(2), 269-282.

Singh, A., \& Bano, S. (2016). Social axioms of young and old people in India: a survey study. International Journal of Indian Psychology, 3(3).

Stankov, L. (2016). Individual differences within the psychological atlas of the world. Personality and Individual Differences, 94, 180-188. 
Stankov, L., \& Saucier, G. (2015). Social axioms in 33 countries. Journal of Cross-Cultural Psychology, 46(2), 296-315.

Stavrova, O., \& Ehlebracht, D. (2016). Cynical beliefs about human nature and income: Longitudinal and cross-cultural analyses. Journal of Personality and Social Psychology, 110(1), 116-132.

Tang, C. S.-K., \& Wu, A. M. S. (2010). Direct and indirect influences of fate control belief, gambling expectancy bias, and self-efficacy on problem gambling and negative mood among Chinese college students: a multiple mediation analysis. Journal of Gambling Studies, 26(4), 533-543.

Tartakovsky, E., \& Hamama, L. (2011). Mothers' acceptance-rejection of their children infected with hiv: the role of the mothers' social axioms, psychological distress, and relationships with the partner. Journal of Pediatric Psychology, 36(9), 1030-1042.

Tartakovsky, E., Gabriel-Fried, B., \& Kovardinsky, S. (2012). P-94 - The relationships between social axioms, therapeutic orientations and burnout among addiction area professionals. European Psychiatry, 27, 1.

Vroom, V. H. (1964). Work and motivation. Wiley.

West, B., Hillenbrand, C., Money, K., Ghobadian, A., \& Ireland, R. D. (2016). Exploring the impact of social axioms on firm reputation: A stakeholder perspective. British Journal of Management, 27(2), 249-270.

Wong, M. M. T., Chen, S. X., \& Wu, W. C. H. (2010). How family matters in shaping offspring worldviews: Personal and interpersonal antecedents of children's social axioms. Journal of Psychology in Chinese Societies, 11(1), 73-90.

Wu, W. C. H., Chen, S. X., \& Wong, S. S.-K. (2019). Predicting gambling propensity and behavior: the role of social axioms and distortive beliefs. Journal of Gambling Studies, 35(3), 969-986.

Zhou, F., Leung, K., \& Bond, M. H. (2009). Social axioms and achievement across cultures: The influence of reward for application and fate control. Learning and Individual Differences, 19(3), 366-371. 